
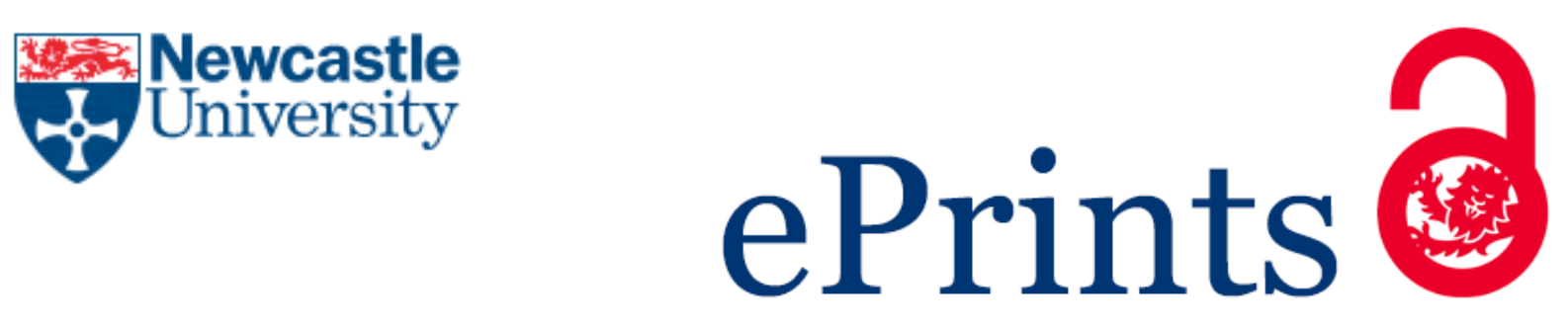

Panchal B, Eddleston M, Thomas SH, Thompson JP, Vale JA.

754 exposures to reed diffusers reported to the United Kingdom National

Poisons Information Service 2010-2014.

Clinical Toxicology 2016, 54(4), 333-338.

\title{
Copyright:
}

This is an Accepted Manuscript of an article published by Taylor \& Francis in Clinical Toxicology on 19/02/2016, available online: http://www.tandfonline.com/10.3109/15563650.2016.1140772

DOI link to article:

http://dx.doi.org/10.3109/15563650.2016.1140772

Date deposited:

03/06/2016

Embargo release date:

19 February 2017

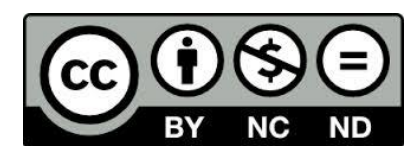

This work is licensed under a

Creative Commons Attribution-NonCommercial-NoDerivatives 4.0 International licence 


\section{4 exposures to reed diffusers reported to the United Kingdom National Poisons Information Service 2010-2014}

B. PANCHAL, ${ }^{1}$ M. EDDLESTON, ${ }^{2}$ S.H.L. THOMAS,${ }^{3}$ J.P. THOMPSON,${ }^{4}$ and J.A. VALE ${ }^{1}$

${ }^{1} N P I S$ (Birmingham Unit), City Hospital, Birmingham, UK

${ }^{2}$ NPIS (Edinburgh Unit), Royal Infirmary, Edinburgh, UK

${ }^{3}$ NPIS (Newcastle Unit), Regional Drug and Therapeutics Centre, Newcastle, UK

${ }^{4}$ NPIS (Cardiff Unit), University Hospital Llandough, Cardiff, UK

Keywords Dipropylene glycol methyl ether acetate; Dipropylene glycol monomethyl ether; Dipropylene glycol n-butyl ether; Ethanol; Isopropanol; 3-methoxy-3-methyl-1butanol; Petroleum distillates; Propylene glycol monobutyl ether 


\begin{abstract}
Objective. To review the reported toxicity of reed diffuser fragrance liquid which, in addition to essential oils, commonly contains glycol ethers but other ingredients and/or alternatives are 3-methoxy-3-methyl-1-butanol, petroleum distillates, ethanol and isopropanol. Methods. We analysed retrospectively enquiries to the United Kingdom National Poisons Information Service between 1st January 2010 and 31st December 2014. Results. 754 patients were exposed to reed diffusers; the majority $(n=712)$ were children $<5$ years. Ingestion was the most common route of exposure (706 of 754 patients) and involved the liquid alone $(n=570)$, water beads alone $(n=84)$, sucking on the reeds $(n=31)$ or ingesting the liquid and water beads $(n=21)$. The reported amount of fragrance liquid ingested was known in only 76 of 591 cases (12.9\%), with a median (IQR) volume of $20.0(I Q R=10-40) \mathrm{mL}$. The WHO/IPCS/EC/EAPCCT Poisoning Severity Score (PSS) was known in 702 of 706 sole ingestions: in $572(81.0 \%)$ the PSS was 0 (asymptomatic); in 119 (16.9\%) patients the PSS was 1 (minor toxicity); in $11(1.6 \%)$ the PSS was 2 (moderate toxicity); there were no patients with features graded PSS 3 (severe toxicity). Significantly ( $p=0.008)$ more patients became symptomatic (PSS 1 and PSS 2) following the ingestion of a reed diffuser containing 3-methoxy-3-methyl-1-butanol than propylene glycol monobutyl ether, though there was no significant difference when compared with those containing dipropylene glycol monomethyl ether $(p=0.181)$. The most common features following ingestion of fragrance liquid were nausea and vomiting $(n=53)$; coughing $(n=17)$ and CNS depression $(n=9)$. Seven patients suffered eye exposure alone: two developed eye pain and four conjunctivitis. Dermal exposure alone was reported in six patients, two of whom developed skin irritation. Conclusions. The majority of patients in our study developed no features or only minor symptoms following ingestion of reed diffuser fragrance liquid.
\end{abstract}




\section{Introduction}

Over the past decade, the air freshener industry has introduced a diversity of air care products including aerosol and automatic sprays, fragrance atomizers, electrical plug-ins, gel based fragrances, scented candles and reed diffusers.

There have only been four reports (all abstracts of conference proceedings) on the toxicity of reed diffusers. Crandon et al. ${ }^{1}$ reported that the Cardiff Unit of the National Poisons Information Service (NPIS) had received 27 telephone enquiries regarding exposure to reed diffusers from January to November 2009, though limited clinical data were included. Two other reports detailed the clinical course of two young children who ingested fragrance liquid from a reed diffuser that contained 3-methoxy-3-methyl-1butanol, ${ }^{2,3}$ and a subset of the data reported in this paper have been published by us in abstract previously. ${ }^{4}$

A typical reed diffuser (Fig. 1) consists of a glass vessel containing fragrance liquid and "wicking" reeds, which help to diffuse the scent of the fragrance liquid into the room and are usually made of rattan. The volume of liquid inside a reed diffuser ranges between 20-500 $\mathrm{mL}$, with large volume diffusers providing air freshening for up to six months. The large open neck of the vessel readily allows young children access to the liquid. Reed diffusers may also contain water beads for decorative purposes.

The chemical composition of the fragrance liquid varies (Table 1). In addition to a complex mixture of natural and synthetic fragrances including essential oils, the majority of reed diffusers contain glycol ethers (propylene glycol monobutyl ether, dipropylene glycol monomethyl ether, dipropylene glycol n-butyl ether and dipropylene glycol methyl ether acetate); other ingredients and/or alternatives are 3-methoxy-3-methyl-1-butanol, petroleum distillates, ethanol and isopropanol.

This study reviews the toxicity of reed diffusers as reported to the United Kingdom (UK) NPIS over five years (2010-2014).

\section{Methodology}

The NPIS provides information and evidence-based management advice about individual substances through its online database TOXBASE ${ }^{8}$ and its 24 hour telephone advice service, staffed by information scientists and supported by a rota of consultant clinical 
toxicologists. A retrospective analysis of telephone enquiries to the UK NPIS regarding reed diffusers was undertaken for the period 1st January 2010 to 31st December 2014. Data extracted from these enquiries included: age of patient; route(s) of exposure; source of enquiry; location of exposure; circumstances of exposure; product brand; features reported; WHO/IPCS/EC/EAPCCT Poisoning Severity Score (PSS) ${ }^{5}$ that was assigned by NPIS scientific staff at the time of the enquiry. Enquiries received from outside the UK were excluded from this study. GraphPad Prism $6^{\mathrm{TM}}$ was used to calculate the chisquared test (significance level $<0.05$ ). Data on composition was obtained from the NPIS Product Data Centre which contains SDS on UK products. This study did not require approval by a Research Ethics Committee as ethical approval is not needed in the UK for research studies that use information collected routinely as part of usual clinical care, provided this information is passed to the researchers in a fully anonymised format.

\section{Results}

Eight hundred and eighteen enquiries involving 754 exposures to reed diffusers were reported to the UK NPIS over the five year period 2010-2014; 64 enquiries provided additional information on 62 of the 754 patients. The number of enquiries increased from 61 per year in 2010 to 257 in 2014, with a similar increase in the number of reported exposures (Fig. 2). The 818 enquiries were received from NHS Direct/NHS111/NHS 24 [these services provide the public with advice on health issues $(n=350 ; 42.8 \%)$ ]; hospitals $(n=335 ; 41.0 \%)$; general practices, including out-of-hours services $(n=99 ; 12.1 \%)$; ambulance services $(n=26 ; 3.2 \%)$; walk-in-centres $(n=6 ; 0.7 \%)$ and community pharmacies $(n=2 ; 0.2 \%)$.

The age of the patient was known in 745 out of 754 exposures. Of these 745 exposures, 712 (95.5\%) were children $<5$ years old [637 (85.5\%) were children $<3$ years of age], 14 were children between the ages of 5 and $<10$ years old and 19 involved patients $\geq 10$ years old. Two of these 19 patients (aged 10 and 33 years respectively) had learning difficulties and one was pregnant. Of the 754 exposures, 753 occurred at home; a single exposure occurred in the workplace.

Ingestion alone accounted for $93.6 \%(n=706)$ of exposures; eye contact alone $(n=7 ; 0.9 \%)$, skin contact alone $(n=6 ; 0.8 \%)$ and multiple routes of exposure $(n=35 ; 4.6 \%)$ 
were also reported.

The company marketing the reed diffuser was known in 505 of $754(67.0 \%)$ exposures. However in 26 cases, although the company was known, the specific brand was not, which prevented identification of the product. Additionally, in one case, we were unable to identify the ingredients because the safety datasheet (SDS) was not provided by the company concerned, despite several requests. As a result, the main ingredients in the fragrance liquid were identified in only 478 of 754 preparations (Table 1).

The WHO/IPCS/EC/EAPCCT Poisoning Severity Score (PSS) was determined in 749 of 754 exposures: 596 (79.0\%) patients were asymptomatic (PSS 0), 142 (18.8\%) developed minor toxicity (PSS 1), 11 (1.5\%) moderate toxicity (PSS 2); no exposures resulted in severe toxicity (PSS 3).

\section{Ingestion}

Five-hundred and ninety-one of 754 patients ingested fragrance liquid, including 21 who had co-ingested water beads. The majority of these exposures occurred in children $<3$ years of age (85.3\%). Exposures occurred predominantly in boys with a male: female ratio of $1.25: 1$ in asymptomatic patients and $1.51: 1$ in symptomatic patients. The age and gender could not be determined in five children. In two cases it was unknown whether a boy and girl developed symptoms following exposure.

The symptoms reported following the ingestion of different components of a reed diffuser are shown in Table 2 and the PSS following the ingestion of liquid alone or with water beads, water beads alone or after sucking on the reed(s) are shown in Table 3. The reported amount of fragrance liquid ingested was known in only 76 of 591 cases (12.9\%), with a median $(I Q R)$ volume of $20.0(I Q R=10-40) \mathrm{mL}$.

A comparison of PSS against the main ingredient in the fragrance liquid is shown in Table 4. Significantly $\left(\chi^{2}(1)=7.046, p=0.008\right)$ more patients became symptomatic (PSS 1 and PSS 2) following the ingestion of a reed diffuser containing 3-methoxy-3methyl-1-butanol than propylene glycol monobutyl ether, though there was no significant difference when compared with patients who became symptomatic following ingestion of fragrance liquid containing dipropylene glycol monomethyl ether $\left(\chi^{2}(1)=1.785, p=0.181\right)$.

Ingestion of the fragrance liquid also occurred in 34 cases that involved additional 
routes of exposure: 19 patients were asymptomatic; 14 patients developed minor symptoms, although only in seven were symptoms (vomiting, hyperactivity, bronchospasm, coughing, spluttering, hiccups, acidosis and drowsiness) related to ingestion. In one case the symptoms were unknown.

\section{Skin exposure}

Skin contact with the fragrance liquid alone occurred in six patients. Two woman aged 20 years and 48 years respectively reported "skin irritation" following exposure. The remaining four patients were children aged $<5$ years old and did not develop features.

Skin contact in combination with other routes of exposure was reported in 34 patients. Thirty-two patients were children aged $<3$ years old, another was 7 -years old and the age of one patient was unknown. In 23 of the 34 exposures involving skin contact, no skin related symptoms were reported. In the remaining ten cases, rash was the main feature and in one case the symptoms were unknown.

\section{Eye exposure}

Eye contact alone occurred in seven patients. Six of these patients were children aged $<2$ years old; the other was an adult. Eye symptoms were reported in six out of these seven exposures: conjunctivitis occurred in four patients and eye pain in two. Eye contact in combination with other routes of exposure was reported in four children. All were aged $<3$ years old. Three patients were symptomatic; conjunctivitis occurred in one, eye irritation in one and eye oedema in one.

\section{Discussion}

The majority of exposures (85.5\%) occurred in children $<3$ years old. This is similar to the age group reported by Crandon et al. ${ }^{1}$ (eight months to four years of age) and consistent with our previous study ${ }^{6}$ that showed that the ingestion of household products is most common (65\%) in those less than 5 years of age, by which time children will have developed the mobility and handling skills that enable them to explore the domestic environment, but not the ability to make decisions that prevent them from ingesting harmful substances. 
No human exposures to propylene glycol monobutyl ether have been described previously, though the experimental oral LD50 of has been reported to be $1.9 \mathrm{~g} / \mathrm{kg}^{7}$ and $4.0 \mathrm{~mL} / \mathrm{kg}^{8}{ }^{8}$ In our study, 228 ingestions involved this chemical, but $84.2 \%$ of patients remained asymptomatic. Conjunctivitis, irritation and eye oedema were observed in five patients and it is known that propylene glycol monobutyl ether can produce moderate irritation and transient corneal opacity experimentally. ${ }^{7}$ Of the ten patients dermally exposed to $10-60 \% \mathrm{w} / \mathrm{w}$ of propylene glycol monobutyl ether, only three developed a rash.

Eighty-seven patients ingested fragrance liquid containing dipropylene glycol monomethyl ether, and 22 developed features including numbness and burning in the mouth, hypersalivation, hypoxia, stridor, bronchospasm, vomiting, drowsiness and a single seizure. Experimentally, dipropylene glycol monomethyl ether is known to produce marked CNS and cardiac depression, with atrial fibrillation and hypotension predominating; death usually follows the onset of respiratory failure..$^{9,10}$ Based on the reported oral LD50 of $5.4,{ }^{10} 5.6^{11}$ and $7.50^{9} \mathrm{~mL} / \mathrm{kg}$ and the highest concentration of dipropylene glycol monomethyl ether found inside a reed diffuser of $90 \% \mathrm{w} / \mathrm{w}$, very significant toxicity would develop if a 2-year-old child with an average weight of $12 \mathrm{~kg}$ ingested $>60 \mathrm{~mL}$ of this fragrance liquid. In our study only one patient was exposed ophthalmically to this chemical (concentration $>50 \% \mathrm{w} / \mathrm{w}$ ) which caused eye pain, but in 10 volunteers it has produced stinging, lacrimation, blepharospasm and conjunctival inflammation. ${ }^{12}$ In our study three patients dermally exposed developed a rash.

Seventeen exposures in our study involved the ingestion of fragrance liquid containing 3-methoxy-3-methyl-1-butanol. The toxicity of this chemical has been highlighted previously in abstract. ${ }^{2,3}$ Two young children developed symptoms including vomiting, excessive salivation, change in phonation, erythema of the face and chest, inflammation of the oesophagus, friable mucosa, mild ataxia and sloughing, following the ingestion of 59-88 $\mathrm{mL}^{3}$ and an unknown amount of fragrance liquid from a reed diffuser. ${ }^{2}$ Both patients made a complete recovery. In our study, seven of 17 patients who ingested fragrance liquid alone containing 3-methoxy-3-methyl-1-butanol developed symptoms, including four patients who had one episode of vomiting, two patients who vomited six times and one patient who suffered diarrhoea. Moreover, significantly $(p=0.008)$ more 
patients became symptomatic following the ingestion of a reed diffuser containing 3methoxy-3-methyl-1-butanol than propylene glycol monobutyl ether.

Our single case involving a child who sucked on the reeds of a diffuser containing dipropylene glycol methyl ether acetate and dipropylene glycol n-butyl ether, did not develop any symptoms, which is unsurprising as exposure by this route would be minimal. However, experimental studies have demonstrated that dipropylene glycol nbutyl ether causes lethargy, lacrimation, piloerection, ataxia and death, ${ }^{13}$ and dipropylene glycol methyl ether acetate has caused death when administered in doses of $10 \mathrm{~mL} / \mathrm{kg}^{7}$

In our study we were able to identify that the fragrance liquid in at least 188 cases of ingestion contained petroleum distillates, usually in a concentration of $1-15 \% \mathrm{w} / \mathrm{w}$, though concentrations of up to $77 \% \mathrm{w} / \mathrm{w}$ are present in some products. However, six patients who had ingested fragrance liquid containing petroleum distillate alone did not develop any symptoms. Ingestion of petroleum distillates may cause vomiting, diarrhoea and abdominal pain; aspiration may result in chemical pneumonitis. ${ }^{14}$

Five exposures involved the ingestion of reed diffuser liquid containing ethanol alone (highest concentration $\geq 70 \% \mathrm{w} / \mathrm{w}$ ). Three were asymptomatic, one suffered an episode of vomiting and the features were unknown in the other. The relative lack of features in our cases would imply these children did not ingest sufficient quantities of the fragrance liquid containing ethanol. A 2-year-old child, with an average weight of $12 \mathrm{~kg}$ would only need to ingest as little as $5.5 \mathrm{~mL}$ of a preparation containing $70 \%$ w/w ethanol to develop features.

Four exposures involved the ingestion of a reed diffuser containing isopropanol $(10.5-13 \% \mathrm{w} / \mathrm{w})$ in addition to ethanol $(57 \% \mathrm{w} / \mathrm{w})$; two patients remained asymptomatic and two developed vomiting. The ingestion of less than $30 \mathrm{~mL}$ of isopropanol is unlikely to cause features. ${ }^{15}$ Hence small ingestions are unlikely to elicit symptoms of CNS depression, though the presence of ethanol may lead to additional toxicity.

The majority of reed diffusers in our study contained a fragrance mixture consisting of natural and synthetic fragrances including essential oils which were present in concentrations up to $30 \% \mathrm{w} / \mathrm{w}$ in some preparations. The clinical effects of essential oils include dysaesthesia inside the mouth, nausea, vomiting, tachycardia, drowsiness and in severe cases convulsions and coma. ${ }^{16,17}$ It is difficult to determine whether the essential 
oils were responsible for any of the symptoms reported in our study, though they may have contributed to the development of nausea and vomiting, drowsiness, lip swelling, redness and irritation, sore mouth, pharyngitis and a tonic-clonic convulsion. ${ }^{17}$ In addition, essential oils may be aspirated following ingestion and this may have led to some of the respiratory features that were reported in this study including coughing, gagging, bronchospasm/wheeze, stridor and choking.

There are two main limitations to our study. No organised follow up of enquiries took place, though additional information was available in 62 cases from further enquiries $(n=64)$; thus the further clinical course on $92 \%$ of patients was not known. Furthermore, unlike most other countries, the UK NPIS does accept telephone enquiries from members of the public. Hence these data may not represent the total number of exposures to reed diffusers that occur in the UK, though it is likely to include most if not all of the more severe presentations.

\section{Conclusions}

Overall this large case series has demonstrated that while the majority of patients remain asymptomatic following the ingestion of reed diffuser liquid, a small number of children develop features that require medical intervention.

\section{Acknowledgement}

We are grateful to Damian Ballam, NPIS (Birmingham Unit), for statistical advice.

\section{Declaration of interest}

The authors report no declaration of interest. 


\section{References}

1. Crandon KC, Davies JTD, Thompson JP. Reed diffuser toxicity. Clin Toxicol 2010; 48:285.

2. Staton-Growcock ST, Sztajnkrycer MD. First reported human oral exposure to a reed diffuser air freshener containing 3-methoxy-3-methyl-1-butanol (MMB). Clin Toxicol 2007; 45:612.

3. Strickland SS, Whitlow KS. Toxic effects from human oral exposure to 3-methoxy-3methyl-1-butanol (MMB). Clin Toxicol 2008; 46:643.

4. Panchal B, Eddleston M, Thomas SHL, Thompson JP, Vale JA. Toxicity of reed diffusers: a retrospective analysis of telephone enquiries to the UK National Poisons Information Service 2010-2012. Clin Toxicol 2014; 52:340.

5. Persson HE, Sjöberg GK, Haines JA, De Garbino JP. Poisoning severity score. Grading of acute poisoning. J Toxicol Clin Toxicol 1998; 36:205-13.

6. Williams H, Moyns E, Bateman DN, Thomas SHL, Thompson JP, Vale JA. Hazard of household cleaning products: a study undertaken by the UK National Poisons Information Service. Clin Toxicol 2012; 50:770-775.

7. Cragg ST. Glycol ethers: ethers of propylene, butylene glycols, and other glycol derivatives. In: Bingham E, Cohrssen B, editors. Patty's toxicology. 6 ed. New York: John Wiley \& Sons; 2012. p. 789-877.

8. Smyth HF, Jr., Carpenter CP, Weil CS, Pozzani UC, Striegel JA, Nycum JS. Rangefinding toxicity data: list VII. Am Ind Hyg Assoc J 1969; 30:470-476.

9. Shideman FE, Procita L. The pharmacology of the mono methyl ethers of mono-, di-, and tripropylene glycol in the dog with observations on the auricular fibrillation produced by these compounds. J Pharmacol Exp Ther 1951; 102:79-87.

10. Rowe VK. Toxicology of mono-, di- and tripropylene glycol methyl ethers. Arch Ind Hyg Occup Med 1954; 9:509-25.

11. Smyth HF, Jr., Carpenter CP, Well CS, Pozzani UC, Striegel JA. Range-finding toxicity data: list VI. Am Ind Hyg Assoc J 1962; 23:95-107.

12. Ballantyne B. Local ophthalmic effects of dipropylene glycol monomethyl ether. J Toxicol Cutan Ocul Toxicol 1983; 2:229-42.

13. Myers RC, Tyler TR. Acute toxicologic evaluation of dipropylene glycol monobutyl ether. Journal of the American College of Toxicology Part B, Acute toxicity data 1992; $1: 172$.

14. Tormoehlen LM, Tekulve KJ, Nañagas KA. Hydrocarbon toxicity: a review. Clin Toxicol 2014; 52:479-89. 
15. Stremski E, Hennes $\mathrm{H}$. Accidental isopropanol ingestion in children. Pediatr Emerg Care 2000; 16:238-40.

16. Woolf A. Essential oil poisoning. J Toxicol Clin Toxicol 1999; 37:721-27.

17. Bateman DN. Essential oils. In: Bateman DN, Jefferson RD, Thomas SHL, Thompson JP, Vale JA, editors. Oxford desk reference: toxicology. Oxford: Oxford University Press; 2014. p. 234-35. 
Table 1. Chemical composition of fragrance liquid involved in 478 exposures (all routes)

\begin{tabular}{|c|c|c|}
\hline Main ingredient & Exposures $\mathrm{n}=$ & Brand \\
\hline $\begin{array}{l}\text { Dipropylene glycol } \\
\text { monomethyl ether }\end{array}$ & 101 & 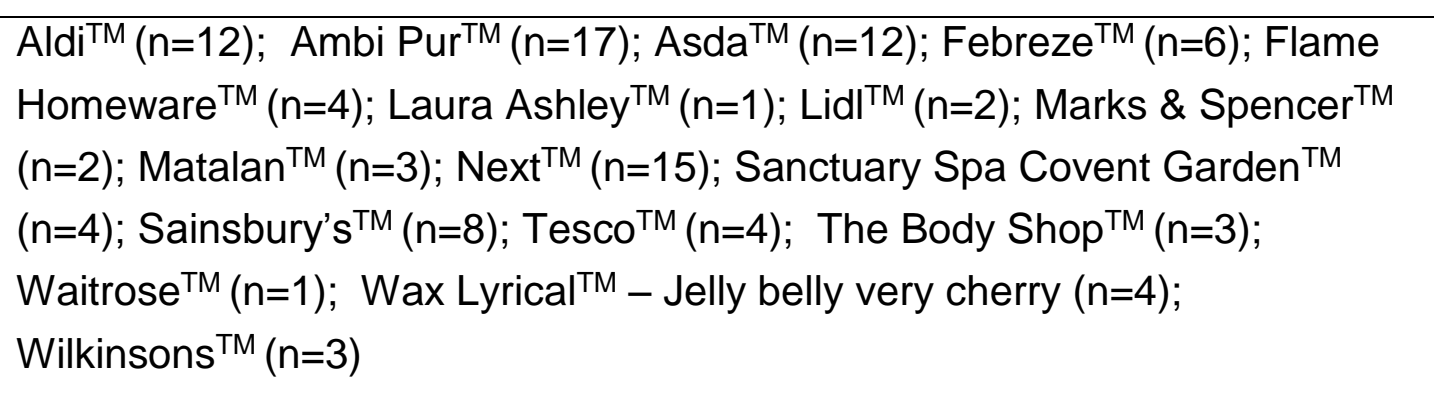 \\
\hline $\begin{array}{l}\text { Propylene glycol } \\
\text { monobutyl ether }+ \\
\text { petroleum distillates }\end{array}$ & 322 & Air Wick ${ }^{T M}$ \\
\hline $\begin{array}{l}\text { 3-methoxy-3-methyl-1- } \\
\text { butanol }\end{array}$ & 22 & $\begin{array}{l}\text { The White Company }{ }^{\mathrm{TM}}-\text { reed diffuser base solvent }(n=1)^{*} \text {; Yankee Candle } e^{\mathrm{TM}} \\
(\mathrm{n}=21)\end{array}$ \\
\hline $\begin{array}{l}\text { Petroleum distillates } \\
\text { alone }\end{array}$ & 6 & The Body Shop ${ }^{T M}$ \\
\hline Ethanol + isopropanol & 5 & Wax Lyrical ${ }^{\mathrm{TM}}$ - Colony reed diffuser \\
\hline Ethanol alone & 6 & $\begin{array}{l}\text { Fikkerts }^{\top M}(n=1) ; \text { Millefiori }^{\top M}(n=1) \text {; Orla Keily } \\
\text { Rituals }^{T M}(n=1) \text {; Pecksniff }(n=1)\end{array}$ \\
\hline Water & 8 & Airpure $^{\mathrm{TM}}$ \\
\hline Fragrance (100\%) & 8 & Glade $^{T M}$ \\
\hline
\end{tabular}

${ }^{*}$ The White Company ${ }^{\mathrm{TM}}$ reed diffusers also contain dipropylene glycol n-butyl ether and dipropylene glycol methyl ether acetate 
Table 2. Clinical features reported following the ingestion of fragrance liquid alone or with water beads, water beads alone or sucking on the reeds

\begin{tabular}{|c|c|c|c|}
\hline Features & $\begin{array}{c}\text { Ingestion of fragrance } \\
\text { liquid alone }(n=570) \text { or } \\
\text { with water beads }(n=21) \text {; } \\
(\% \text { of } 591)\end{array}$ & $\begin{array}{l}\text { Ingestion of water } \\
\text { beads alone } n=84 \\
\text { (\%) }\end{array}$ & $\begin{array}{l}\text { Sucking on the } \\
\text { reeds alone } n=31 \\
\text { (\%) }\end{array}$ \\
\hline Nausea and vomiting & $53(9.0)$ & $6(7.1)$ & $1(3.2)$ \\
\hline Coughing & $17(2.9)$ & $0(0.0)$ & $0(0.0)$ \\
\hline Drowsiness & $9(1.5)$ & $0(0.0)$ & $0(0.0)$ \\
\hline Sore mouth & $5(0.9)$ & $0(0.0)$ & $0(0.0)$ \\
\hline Diarrhoea & $4(0.7)$ & $0(0.0)$ & $1(3.2)$ \\
\hline Rash & $4(0.7)$ & $0(0.0)$ & $0(0.0)$ \\
\hline Abdominal pain & $3(0.5)$ & $0(0.0)$ & $0(0.0)$ \\
\hline Abnormal gait & $3(0.5)$ & $1(1.2)$ & $0(0.0)$ \\
\hline Gagging & $3(0.5)$ & $1(1.2)$ & $0(0.0)$ \\
\hline $\begin{array}{l}\text { Lip swelling, lip } \\
\text { redness or irritation }\end{array}$ & $3(0.5)$ & $1(1.2)$ & $1(3.2)$ \\
\hline Pharyngitis & $3(0.5)$ & $0(0.0)$ & $1(3.2)$ \\
\hline Bronchospasm/wheeze & $2(0.3)$ & $0(0.0)$ & $0(0.0)$ \\
\hline Dysphonia & $2(0.3)$ & $1(1.2)$ & $0(0.0)$ \\
\hline Hypersalivation & $2(0.3)$ & $0(0.0)$ & $0(0.0)$ \\
\hline Hypoxia & $2(0.3)$ & $0(0.0)$ & $0(0.0)$ \\
\hline Pallor & $2(0.3)$ & $0(0.0)$ & $0(0.0)$ \\
\hline Thirst & $2(0.3)$ & $0(0.0)$ & $0(0.0)$ \\
\hline Tonic-clonic convulsion & $2(0.3)$ & $1(1.2)$ & $0(0.0)$ \\
\hline Abnormal anion gap & $1(0.2)$ & $0(0.0)$ & $0(0.0)$ \\
\hline Acidosis & $1(0.2)$ & $0(0.0)$ & $0(0.0)$ \\
\hline Belching & $1(0.2)$ & $0(0.0)$ & $0(0.0)$ \\
\hline Bradypnoea & $1(0.2)$ & $0(0.0)$ & $0(0.0)$ \\
\hline Choking & $1(0.2)$ & $0(0.0)$ & $0(0.0)$ \\
\hline \multirow[t]{2}{*}{ Decreased appetite } & $1(0.2)$ & $0(0.0)$ & $0(0.0)$ \\
\hline & & 13 & \\
\hline
\end{tabular}




\begin{tabular}{lccc} 
Dyspnoea & $1(0.2)$ & $0(0.0)$ & $0(0.0)$ \\
Ectopic beats & $1(0.2)$ & $0(0.0)$ & $0(0.0)$ \\
Epiglottic swelling & $1(0.2)$ & $0(0.0)$ & $0(0.0)$ \\
Euphoria & $1(0.2)$ & $0(0.0)$ & $0(0.0)$ \\
Facial oedema & $1(0.2)$ & $0(0.0)$ & $0(0.0)$ \\
Haemoptysis & $1(0.2)$ & $0(0.0)$ & $0(0.0)$ \\
Headache & $1(0.2)$ & $0(0.0)$ & $0(0.0)$ \\
Lacrimation increased & $1(0.2)$ & $0(0.0)$ & $0(0.0)$ \\
Numbness in mouth & $1(0.2)$ & $0(0.0)$ & $0(0.0)$ \\
Stridor & $1(0.2)$ & $0(0.0)$ & $0(0.0)$ \\
Tachycardia & $1(0.2)$ & $1(1.2)$ & $0(0.0)$ \\
Taste perversion & $1(0.2)$ & $0(0.0)$ & $0(0.0)$ \\
Urea increase & $1(0.2)$ & $0(0.0)$ & $0(0.0)$ \\
Tongue & $1(0.2)$ & $0(0.0)$ & $1(3.2)$ \\
irritation/blistering & $1(0.2)$ & $0(0.0)$ & $0(0.0)$ \\
Tremor & $0(0.0)$ & $1(1.2)$ & $0(0.0)$ \\
Bloody stools & $0(0.0)$ & $1(1.2)$ & $0(0.0)$ \\
Fever & $3(0.5)$ & $1(1.2)$ & $0(0.0)$ \\
Unknown & $473(80.0)$ & $73(86.9)$ & $26(83.9)$ \\
None & & & \\
\hline
\end{tabular}


Table 3. Poisoning Severity Score ${ }^{5}$ following the ingestion of the different components inside a reed diffuser

\begin{tabular}{|c|c|c|c|}
\hline PSS & $\begin{array}{l}\text { Ingestion of fragrance } \\
\text { liquid alone ( } n=570) \text { or } \\
\text { with water beads } \\
(n=21)(\% \text { of } 591)\end{array}$ & $\begin{array}{l}\text { Ingestion of water } \\
\text { beads alone } n=84(\%)\end{array}$ & $\begin{array}{l}\text { Sucking on the reeds } \\
\text { alone } n=31(\%)\end{array}$ \\
\hline PSS 0 & $473(80.0)$ & $73(86.9)$ & $26(83.9)$ \\
\hline PSS 1 & $105(17.8)$ & $9(10.7)$ & $5(16.1)$ \\
\hline PSS 2 & $10(1.7)$ & $1(1.2)$ & 0 \\
\hline PSS 3 & 0 & 0 & 0 \\
\hline Unknown & $3(0.5)$ & $1(1.2)$ & 0 \\
\hline
\end{tabular}


Table 4. Comparison of main ingredient(s) and Poisoning Severity Score 5 in patients who had ingested reed diffuser fragrance liquid alone or with water beads $(n=591)$.

\begin{tabular}{|c|c|c|c|c|}
\hline Ingredients & $\begin{array}{r}\text { PSS } 0 \\
\text { n (\%) }\end{array}$ & $\begin{array}{r}\text { PSS } 1 \\
\mathrm{n}(\%) \\
\end{array}$ & $\begin{array}{r}\text { PSS } 2 \\
\text { n (\%) } \\
\end{array}$ & $\begin{array}{r}\text { Unknown } \\
\mathrm{n}(\%) \\
\end{array}$ \\
\hline Propylene glycol monobutyl ether $(n=228)$ & $192(84.2)$ & $34(15.0)$ & $2(0.9)$ & $0(0.0)$ \\
\hline Dipropylene glycol monomethyl ether $(n=87)$ & $65(74.7)$ & $19(21.8)$ & $3(3.4)$ & $0(0.0)$ \\
\hline 3-methoxy-3-methyl-1-butanol $(n=17)$ & $10(58.8)$ & $5(29.4)$ & $2(11.8)$ & $0(0.0)$ \\
\hline Petroleum distillate alone $(n=6)$ & $6(100.0)$ & $0(0.0)$ & $0(0.0)$ & $0(0.0)$ \\
\hline Water $(n=8)$ & $5(62.5)$ & $3(37.5)$ & $0(0.0)$ & $0(0.0)$ \\
\hline Ethanol with isopropanol $(n=4)$ & $2(50.0)$ & $2(50.0)$ & $0(0.0)$ & $0(0.0)$ \\
\hline Ethanol alone $(n=5)$ & $3(60.0)$ & $1(20.0)$ & $0(0.0)$ & $1(20.0)$ \\
\hline $100 \%$ Fragrance $(n=7)$ & $6(85.7)$ & $1(14.3)$ & $0(0.0)$ & $0(0.0)$ \\
\hline $\begin{array}{l}\text { Reed diffuser brand known but specific product not } \\
\text { known }(n=24)\end{array}$ & 20 (83.3) & $4(16.7)$ & $0(0.0)$ & $0(0.0)$ \\
\hline Reed diffuser brand not known $(n=205)$ & $164(80.0)$ & $36(17.6)$ & $3(1.5)$ & $2(1.0)$ \\
\hline
\end{tabular}




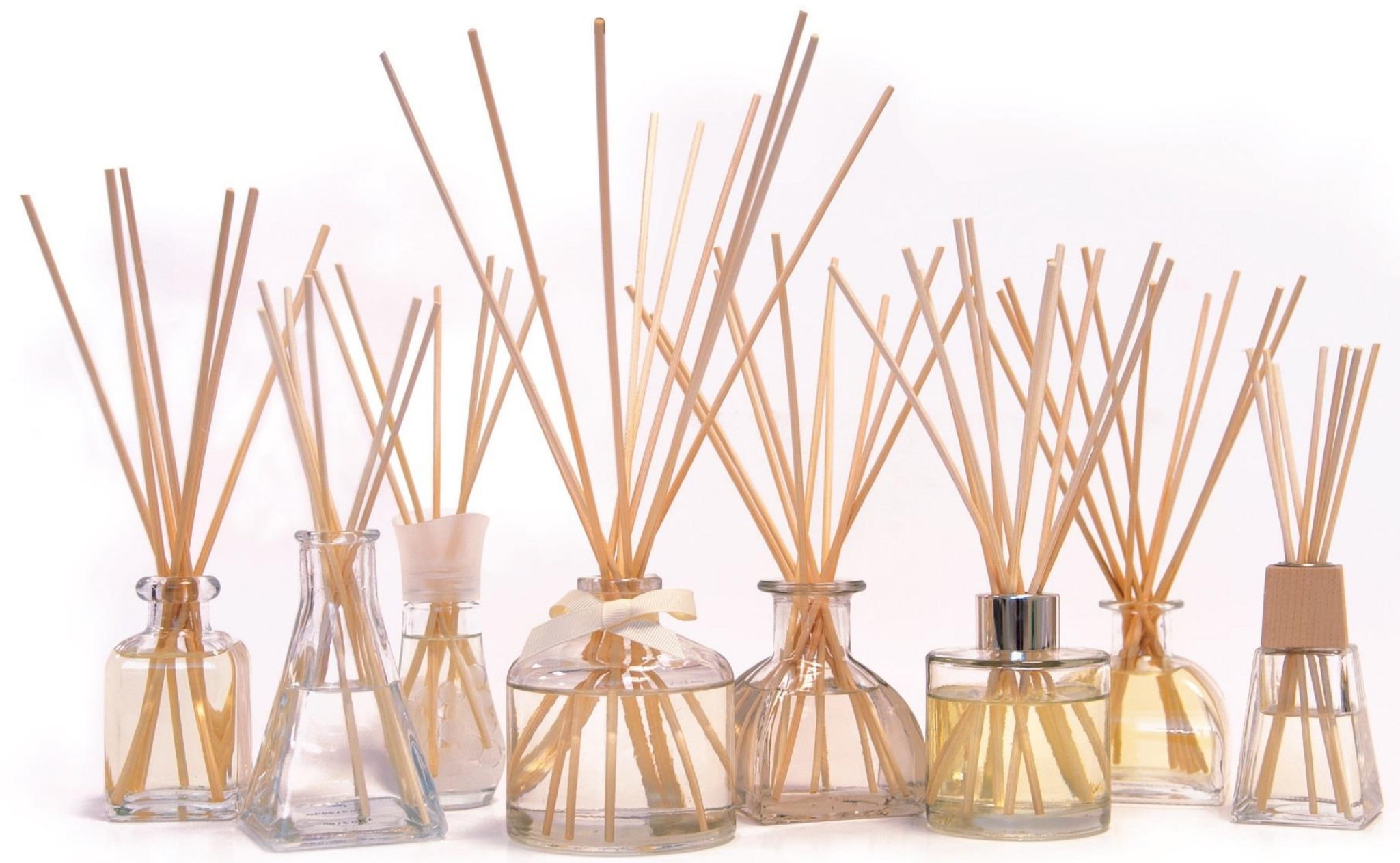

Fig. 1. Examples of reed diffusers sold in the United Kingdom @ Reckitt Benckiser and used with permission 


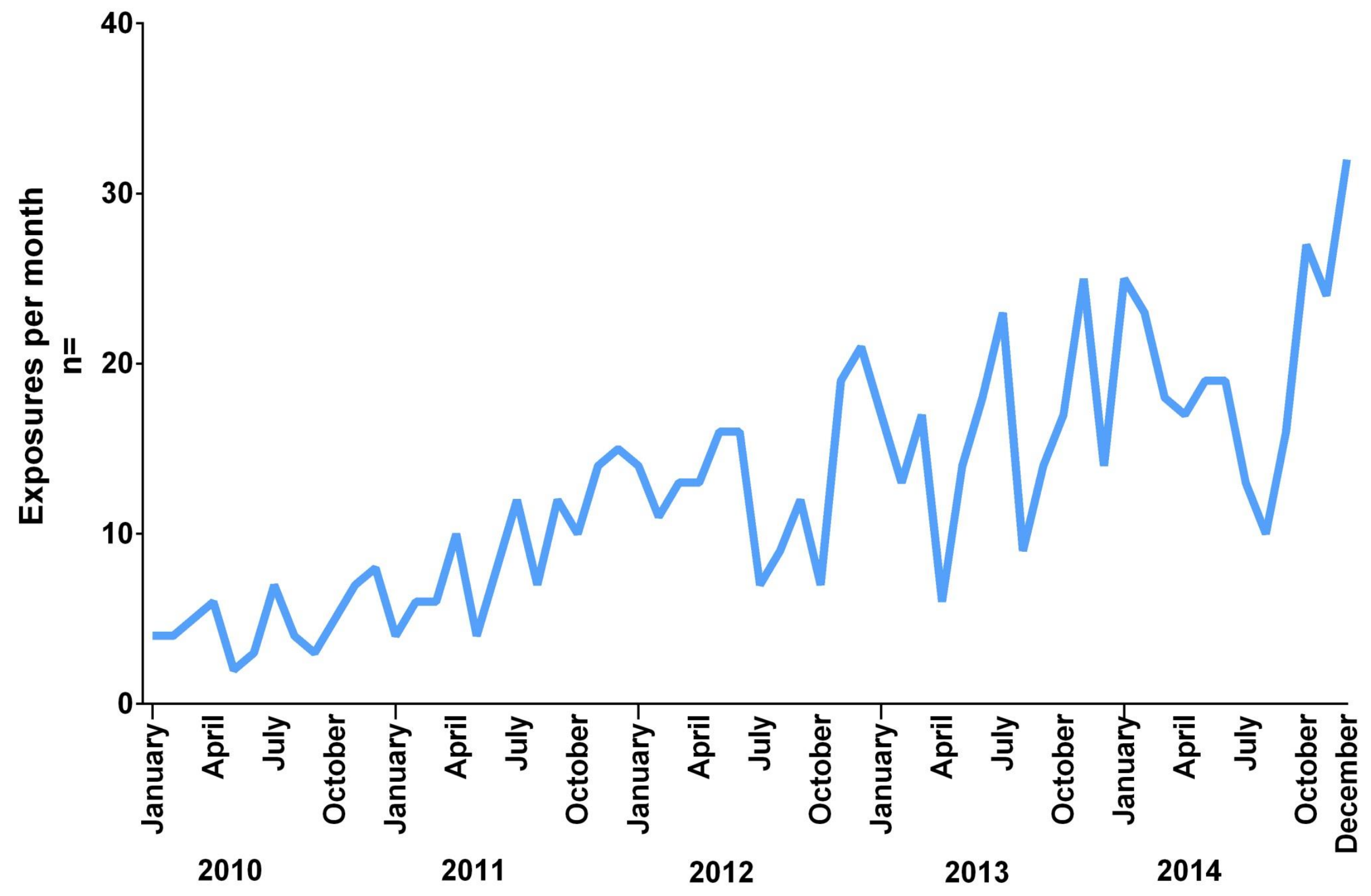

Fig. 2. Number of exposures per month regarding reed diffusers reported to the UK NPIS between 2010-2014 